\title{
JUDICIALIZAÇÃO DA SAÚDE: A OBRIGATORIEDADE DO ESTADO EM FORNECER MEDICAMENTO/TRATAMENTO SEM PREVISÃO NO SISTEMA PÚBLICO, DE ALTO

\author{
CUSTO OU SEM EFICÁCIA COMPROVADA
}

Claudine Ceolla Gaudêncio Knoblauch ${ }^{1}$

Levi Hülse ${ }^{2}$

Joel Haroldo Baade ${ }^{3}$

Recebido em: 20 ago. 2018

Aceito em: 06 dez. 2018

\begin{abstract}
RESUMO: A Constituição Federal de 1.988 traz em seu conteúdo princípios constitucionais de extrema importância, tais como, o princípio da isonomia ou da igualdade e o princípio da dignidade da pessoa humana. O primeiro especifica, segundo a máxima Aristotélica, o tratamento igualitário a todos em situação de igualdade e desigual ao desiguais na medida de suas desigualdades. Já o segundo, tem caráter subjetivo e pressupõe as condições mínimas que garantam a um indivíduo uma vida digna. Com caráter protetivo, a Constituição Federal visa assegurar aos cidadãos um rol de direitos fundamentais, entre eles a saúde. Tratam-se de prestações positivas atribuídas ao Estado que, em suma, deve assegurar o acesso à saúde a todos os cidadãos de maneira universal, integral e igualitária em todo o território nacional. Assim, para dar atendimento ao disposto no texto constitucional políticas públicas são desenvolvidas seguindo os parâmetros definidos pela Lei Orgânica da Saúde (LOS), Lei $n^{\circ} 8080 / 90$, pela Lei $n^{\circ} 8.142 / 90$. Temos também a Lei $n^{\circ}$ 12.401/11 e a Lei no 9.782/99, sendo que esta criou a Agência Nacional de Vigilância Sanitária e aquela criou a Comissão Nacional de Incorporação de Tecnologias no Sistema Único de Saúde. Inobstante a todo aparato legal criado para dar cumprimento ao dever do Estado em disponibilizar serviços de saúde à população, evidencia-se que na prática tal prestação por parte deste é ineficiente levando à crescente judicialização da saúde, atribuindo-se ao Poder Judiciário o dever de, mesmo que indiretamente, interferir em questões administrativas e orçamentárias de atribuição do Poder Executivo, no que diz respeito às questões de saúde.
\end{abstract}

Palavras-chave:

\section{JUDICIALIZATION OF HEALTH: THE OBLIGATION OF THE STATE TO PROVIDE} MEDICATION / TREATMENT WITHOUT FORECASTING IN THE PUBLIC, HIGH COST

\footnotetext{
1Bacharel em Direito pela Universidade Alto Vale do Rio do Peixe - Caçador - SC.

2 Doutorando em Ciência Jurídica pela Universidade do Vale do Itajaí- UNIVALI - SC, na área de concentração em Constitucionalismo, Transnacionalidade e Produção do Direito. Mestre em Ciência Jurídica pela UNIVALI. Graduado Bacharel em Direito pela Fundação Universidade Regional de Blumenau FURB (2010) e graduado em História pela Fundação Universidade Regional de Blumenau FURB (2006). Advogado com a OAB/SC 31.986. Professor na Universidade do Alto Vale do Rio do Peixe - UNIARP. O autor agradece ao Fundo de Apoio à Pesquisa (FAP) da UNIARP pelo apoio financeiro. E-mail: levi@uniarp.edu.br.

3 Doutor. Docente e pesquisador dos Programas de Pós-Graduação em Desenvolvimento e Sociedade e Profissional em Educação da Universidade Alto Vale do Rio do Peixe - UNIARP. E-mail: baadejoel@gmail.com.
} 


\section{OR PROHIBITED EFFECTIVENESS SYSTEM}

ABSTRACT: The Federal Constitution of 1988 brings in its content constitutional principles of extreme importance, such as the principle of equality or equality and the principle of the dignity of the human person. The first specifies, according to the Aristotelian maxim, equal treatment to all in a situation of equality and unequal to the unequal in the measure of their inequalities. The second is subjective and presupposes the minimum conditions that guarantee an individual a dignified life. With a protective character, the Federal Constitution aims to assure citizens a list of fundamental rights, among them health. These are positive benefits attributed to the State, which, in short, must ensure access to health for all citizens in a universal, integral and egalitarian manner throughout the national territory. Thus, in order to comply with the provisions of the constitutional text, public policies are developed following the parameters defined by the Organic Law of Health (LOS), Law n 8080/90, by Law n. 8.142 / 90. We also have Law No. 12,401 / 11 and Law No. 9,782 / 99, which created the National Health Surveillance Agency and created the National Commission for the Incorporation of Technologies into the Single Health System. compliance with the State's duty to provide health services to the population, it is evident that in practice this provision on the part of the latter is inefficient leading to a growing judicialization of health, being attributed to the Judiciary the duty, even indirectly, to interfere in administrative and budgetary matters of attribution of the Executive Power, with regard to health issues.

Keywords: Constitutional principles. Principle of Equality. Principle of the Dignity of the Human Person. Unified Health System. Judicialization of health.

\section{INTRODUÇÃO}

A saúde, listada na Constituição Federal de 1988 como um dos direitos fundamentais sociais, deve ser oferecido pelo Estado a todos os cidadãos de maneira integral e universal. Diante disso, e em razão da crescente busca pelos serviços de saúde, associada à ineficácia do Estado em oferecê-los à coletividade, resulta o aumento das demandas judiciais para garantir o direito individual do cidadão ao acesso a uma saúde de qualidade.

Entre os que recorrem ao judiciário para garantir o pleno restabelecimento de sua saúde encontramos aqueles que buscam o direito de recebimento de tratamentos não padronizado pelo Sistema Único de Saúde - SUS, de alto custo e/ou sem eficiência comprovada (tratamentos experimentais) pelos órgãos regulamentadores.

Desta maneira, nasce o fenômeno da Judicialização da Saúde em que o Poder Judiciário é instado as dirimir as questões de saúde ocasionando sua interferência, mesmo que indireta, nas questões administrativas e orçamentárias atribuídas ao Poder Executivo e, ao conceder tais tratamentos em desacordo com os órgãos de regulação e orçamento, para satisfazer questões individuais de saúde pode comprometer o oferecimento dos serviços de saúde a coletividade. 


\section{DA PREVISÃO CONSTITUCIONAL: DIREITO A SAÚDE COMO DIREITO SOCIAL}

Constam na Constituição Federal os princípios norteadores do sistema de normas e que especificam quais serão as prioridades da nova ordem constitucional. Tais são denominados princípios constitucionais e são elementos inspiradores dos direitos sociais previstos no artigo $6^{\circ}$ da Constituição Federal (BRASIL, 1988), entre eles, a saúde. Com o intuito de delinear o estudo da judicialização da saúde o presente trabalho abordará o conceito, inicialmente de princípios, com posterior análise do princípio da isonomia e do princípio da dignidade da pessoa humana.

De acordo com José Afonso da Silva (2017, p. 94) "os princípios são ordenações que irradiam e imantam os sistemas de normas". O Autor complementa esta conceituação citando Gomes Canotilho e Vital Moreira, enunciando que os princípios "são núcleos de condensações nos quais confluem valores e bens constitucionais". (SILVA, 2017, p. 94).

Assim, conclui-se que existem princípios que se traduzem em normas constitucionais ou que interferem diretamente nestas normas aos quais denomina-se princípios Constitucionais e que os princípios Fundamentais, por sua vez, também conforme José Afonso da Silva (2017, p.95), são princípios de natureza variada sendo difícil conceituá-los precisamente em um "enunciado sintético".

Com o intento de promover esta conceituação o Autor recorre, novamente a Canotilho e Moreira que definem os princípios fundamentais como aqueles que "visam essencialmente definir e caracterizar a colectividade política e o Estado e enumerar as principais opções político constitucionais". (CANOTILHO, MOREIRA apud SILVA, 2017, p. 95)

Assim, os princípios devem ser adequadamente denominados de normas fundamentais ao invés de normas particulares de mero desdobramento analítico e, para Gomes Canotilho, constituem-se "dos princípios definidores da forma de Estado, dos princípios definidores da estrutura do Estado, os princípios estruturantes do regime político e dos princípios caraterizadores da forma de governo e da organização política em geral". (CANOTILHO, MOREIRA apud SILVA, 2017, p. 96)

Deve-se fazer uma distinção entre princípios constitucionais fundamentais e princípios gerais do Direito Constitucional. Como exposto anteriormente, os primeiros integram o Direito Constitucional positivo e expressam-se pelas normas fundamentais, normas-síntese ou normas-matriz, que trazem em seu conteúdo os valores políticos fundamentais do legislador constituinte. (SILVA, 2017, p. 97)

Os princípios fundamentais possuem função ordenadora de ação imediata já que diretamente aplicáveis ou capazes de estabelecerem relações político-constitucionais. Os princípios gerais, por sua vez, "formam temas de uma teoria geral do Direito Constitucional, por envolver conceitos gerais, relações, objetos, que podem ter seu estudo destacado da dogmática jurídico-constitucional." (SILVA, 2017, p. 97)

O conhecimento de dois princípios são essenciais ao presente trabalho: O princípio 
da isonomia e o princípio da dignidade da pessoa humana. Consoante Araújo e Júnior, o princípio da igualdade constitui "um dos pilares estruturais" da Constituição Federal. Isso significa que tanto o legislador como o aplicador das leis devem "dispensar atendimento igualitário a todos os indivíduos, sem distinção de qualquer natureza. (ARAÚJO, JÚNIOR, 2006, p.131)

Dignidade da pessoa humana, por sua vez, "é um valor supremo que atrai o conteúdo de todos os direitos fundamentais do homem, desde o direito à vida. "Concebido como referência constitucional unificadora de todos os direitos fundamentais" (CANOTILHO, MOREIRA apud SILVA, 2017, p. 107)

Aplicando-se o disposto ao tema da judicialização da saúde onde se evidencia que as concessões judiciais acabam por proporcionar um tratamento desigual àqueles que seriam, ou seja, em relação aos usuários do Sistema Único de Saúde (SUS) que demandam judicialmente o tratamento médico de que necessitam e em relação ao demais usuários do SUS que não recorrem a via judicial, e isso se dá, conforme se evidencia nas decisões judiciais, em respeito ao princípio da dignidade da pessoa humana.

O que se evidencia é um sopesamento dos dois princípios ante configuração de um conflito entre eles e, assim, "deve-se buscar a conciliação, uma aplicação de cada qual em extensões variadas, segundo a respectiva relevância no caso concreto, sem que se tenha um dos princípios como excluído do ordenamento jurídico por irremediável contradição com o outro. (MENDES, BRANCO, 2017, p.182)

A Carta Magna brasileira de 1.988 é considerada um marco da proteção dos direitos fundamentais e sociais. Denominada Constituição Cidadã inicia o seu título I elencando os princípios fundamentais. Na sequência, o título II faz menção aos direitos e garantias fundamentais, deixando expresso em seu texto a preocupação de se garantir estes direitos promovendo uma ruptura definitiva com os anos de ditadura militar que a antecedeu. (SILVA, 2017, p. 173)

Tais direitos foram incorporados ao rol de direitos do indivíduo com o fim de oferecer uma proteção à dignidade do homem, através das constantes "reinvindicações da classe trabalhadora que, em um cenário de miséria, condições desumanas de trabalho e total exclusão da vida social e política, buscava o amparo estatal para as necessidades relacionadas às condições de trabalho, à educação, à saúde e à moradia. (GOTTI, 2012, cap.2)

O fato de podermos exercer positivamente os direitos fundamentais nos permite exigir dos poderes públicos suas eventuais omissões é de significativa importância ao estudo da judicialização da saúde, haja vista que a busca judicial visando a garantia da saúde se dá, em partes, pela omissão e ineficiência do poder público em oferecê-los de maneira satisfativa. 


\section{DOS RESPONSÁVEIS PELA DEFINIÇÃO DO ROL DE PROCEDIMENTOS DA SAÚDE}

\section{PÚBLICA}

A Constituição da República Federativa do Brasil atribuiu ao poder público a obrigatoriedade da prestação e assistência em saúde, bem como a regulamentação, a fiscalização e o controle das ações públicas destinadas a promoção, proteção e recuperação da saúde.

Com o intuito de implementar o disposto no texto constitucional de 1.988, criou-se, por exemplo, o Sistema Único de Saúde que, entre outras atribuições, controla e fiscaliza os procedimentos, os produtos e as substância de interesse para a saúde. A este sistema gerenciado pelo SUS e cujas atribuições são financiadas por verbas públicas dá-se o nome de Sistema Púbico de Saúde. (GONÇALVES, 2015, p. 102)

A Lei Orgânica da Saúde (LOS), Lei n 8080, editada em 1.990 foi inicialmente discutida na $8^{\circ}$ Conferência Nacional em Saúde, realizada em março de 1.986, que ao seu final elaborou relatório especificando, em síntese, que o sistema nacional de saúde no Brasil deveria ser reestruturado, seguindo-se uma nova concepção em saúde. (REMOR, 2003, p.31)

Tal concepção diz respeito a saúde ser um direito do cidadão e um dever do Estado e não deve ser restrita apenas a assistência médica, sendo resultante de vários fatores sociais. O objetivo essencial da criação do SUS, por sua vez, foi a implementação dos princípios constitucionais, constantes no artigo 196 da Constituição Federal de 1988 que preve a universalidade, integralidade e igualdade de acesso a saúde para toda a população. (REMOR, 2003, p.32)

Em relação ao caráter integral e universal do atendimento que deve ser prestado pelo Estado brasileiro, Sandra Krieger Gonçalves (2015, p.117), conclui que se é dever de Estado o atendimento da população, fornecendo-Ihes profissionais da área médica, exames, atendimento hospitalar e todas as atividades que sejam voltadas a este fim, é deste o dever de operacionalizar através da rede pública o acesso a saúde. O que se vê, ainda de acordo com a autora, é que o Estado não impõe limites de acesso ao serviço público.

Conforme entendimento da juíza de Direito Danielle Coutinho Cunha Gomes (2017, p.198),

o caráter integral confere ao cidadão assistência em saúde, desde o atendimento básico até alta complexidade mas, não confere ao usuário do sistema o direito a todo e qualquer medicamento, produto ou insumo, mas tão somente àquele capaz de atingir seu fim.

Com a implementação da Lei $\mathrm{n}^{\circ} 8080 / 90$ houve a descentralização politica e administrativa com repasse das competências da União para os municípios. A descentralização política configura-se por Estados, assim entendidos como a União, os Estados e os Munícipios, divididos em entes dotados de capacidade política, ou seja, que 
podem criar sua própria ordem jurídica. (REMOR, 2003, p.34)

Oportuno mencionar que a Lei no 8142/90 foi editada como complemento a Lei no 8080/90 para garantir maior participação da comunidade na gestão da saúde pública e, também, em relação às transferências intergovernamentais de recursos financeiros na área da saúde, matérias estas que forma objeto de vetos na lei anterior. (WARGAS, 2014, p.14)

Outro dispositivo legal que garantiu grande avanço da organização do SUS foi a Lei $n^{\circ}$ 12.401/11 que criou a Comissão Nacional de Incorporação de Tecnologias no SUS. Esta lei alterou a LOS e atribuiu a referida comissão o dever de definir a incorporação, exclusão e alteração de medicamento, produtos e procedimentos do SUS como atribuições do Ministério da Saúde, bem como trouxe vedação expressa ao pagamento de medicamentos, produtos e procedimentos não autorizados pela ANVISA (Agência Nacional de Vigilância Sanitária) e dispensação e pagamento de medicamentos, produtos e procedimentos sem o devido registro na ANVISA. (BRASIL. Lei $n^{\circ} 12.401 / 11$ )

A ANVISA, por sua vez, foi instituída pela Lei no 9.782/99, de 26 de janeiro de 1999, que definiu o Sistema Nacional de Vigilância Sanitária e criou a Agência Nacional de Vigilância Sanitária, suas atribuições e competências. (BRASIL. Lei no 9.782/99).

Pode-se citar como exemplo do previsto na lei supramencionada a criação da Relação Nacional de Medicamentos - RENAME, publicada pelo Ministério da Saúde, "no qual consta a lista de medicamentos essenciais para tratar as doenças mais comuns na população, e que apresentam menor custo nas etapas de armazenamento, distribuição, controle e tratamento". (BRASIL. Lei n 9.782/99)

De acordo com Tatiana Wargas (2014, p.14) cabe, também ao Ministério da Saúde, a edição de portarias que "correspondem à síntese das negociações e dos pactos firmados entre os três níveis de direção do SUS - nacional, estadual e municipal, discutida e aprovada pelo Conselho Nacional de Saúde".

Assim, cumpre ao Ministério da Saúde, órgão do poder executivo federal, a função de organização e elaboração de planos e políticas públicas destinadas para a assistência à saúde dos brasileiros, mediante a integração com os demais órgãos federais e entes federativos, visando melhor atender aos interesses da população. (CARVALHO, SANTOS, 2002, p. 131-132)

\section{DAS DEMANDAS JUDICIAIS QUE VISAM OBRIGAR O ESTADO A DISPONIBLIZAR}

MEDICAMENTO/TRATAMENTO NÃO PADRONIZADO, DE ALTO CUSTO OU

\section{EXPERIMENTAL}

Ao iniciar o estudo das demandas judiciais em saúde é necessário analisar as causas da judicialização da saúde. De acordo com o Ministro do Supremo Tribunal Federal Luís Roberto Barroso em artigo intitulado Judicialização, Ativismo Social e Legitimidade 
Democrática.

Ao tratar sobre o tema "A Judicialização da Vida", o Barroso (2017, p.3) afirma que:

Judicialização significa que algumas questões de larga repercussão política ou social estão sendo decididas por órgãos do Poder Judiciário, e não pelas instâncias políticas tradicionais: o Congresso Nacional e o Poder Executivo - em cujo âmbito se encontrar o Presidente da República, seus ministérios e a administração pública em geral.. ${ }^{4}$

Afirma o Autor que a primeira grande causa da judicialização no Brasil foi a redemocratização do país com a promulgação da Constituição de 1988, que fortaleceu e expandiu o Poder Judiciário sendo que este, nas suas palavras, "deixou de ser um departamento técnico especializado e se transformou em um poder político, capaz de fazer valer a Constituição e as leis, inclusive me confronto com outros poderes". (BARROSO, 2017, p.3)

Complementa o Ministro que atualmente há atualmente no Supremo Tribunal Federal uma nova geração de Ministros cuja investidura no cargo se deu após o fim do regime militar. Atrelado a este fato, a reestruturação da democracia reavivou a cidadania e fomentou a informação e a consciência dos direitos em todos os segmentos da população que, por sua vez, passaram a questionar seus interesses perante os tribunais. (BARROSO, 2017, p.3)

Ainda expõe Barroso $(2017$, p.3) que "nesse mesmo contexto, deu-se a expansão institucional do Ministério Público, com aumento da relevância de sua atuação fora da área estritamente penal, bem como a presença crescente da Defensoria Pública em diversas partes do Brasil. A redemocratização, portanto, aumentou a demanda por justiça na sociedade brasileira.

A segunda causa contributiva para o aumento da judicialização, também apontada por Luís Roberto Barroso (2017, p.3), foi a "constitucionalização mais abrangente, que trouxe para a Constituição inúmeras matérias que antes eram deixadas para o processo político majoritário e para a legislação ordinária".

Consoante Barroso $(2017$, p.3):

[...] constitucionalizar uma matéria significa transformar Política em Direito. Na medida em que uma questão - seja um direito individual, uma prestação estatal ou um fim público - é disciplinada em uma norma constitucional, ela se transforma, potencialmente, em uma pretensão jurídica que pode ser formulada sob a forma de ação judicial.

A terceira e última causa da judicialização, apontada pelo Ministro, é o sistema brasileiro de controle de constitucionalidade no Brasil. Considerado um dos mais abrangentes do mundo é classificado como híbrido ou eclético e combina aspectos dos sistemas americano e europeu. (BARROSO, 2017, p.3)

Acerca do tema da judicialização da saúde João Pedro Gebran Neto (2015, p.163)

\footnotetext{
4BARROSO, Luis Roberto. Judicialização, ativismo social e legitimidade democrática. Disponível em http://www.direitofranca.br/direitonovo/FKCEimagens/file/ArtigoBarroso_para_Selecao.pdf. Acesso em 07 nov 2017. p.3
} 
afirma que embora tenha havido significativos avanços deste "ambicioso programa de saúde", o sistema convalece, dentre outros fatores, em razão do subfinanciamento público, da falha de gestão, da falta de fiscalização.

Complementa o autor que: (CLENIO, NETO, 2015, p.163)

Diante deste contexto, a judicialização da saúde se tornou um fenômeno que se multiplicou, a partir de liminares e antecipação de tutelas concedidas pelo Poder Judiciário, obrigando o Estado a prestar aquilo que esta nas políticas públicas, bem como atender reivindicações que não se acham cobertas por estas.

Com o fim de se ver garantido o direito a saúde os seus titulares acabam por recorrer ao Poder Judiciário. Esta procura ocorre por duas frentes distintas, quais sejam, a individual, passando pela atuação de diversas instâncias judiciais como o Ministério Público, a Defensoria Pública e a Advocacia e o coletivo, sendo estes representados pelo Ministério Público. (MACHADO, 2008, p.76)

Em artigo publicado na Revista Direito Sanitário, Felipe Rangel de Souza Machado (2008, p.76) destaca a decisiva participação do Poder Judiciário como "instituição responsável pelo julgamento das questões referentes à concessão ou negação de determinado pleito", devendo interpretar normas e arbitrar sobre sua legalidade e aplicação.

Em relação às decisões judiciais em processos que visam o fornecimento de medicamento e insumos pelo Estado de São Paulo, Silvia Badim Marques e Sueli Gandolfi Dallari (2007, p.103), desenvolveram uma análise destes processos judiciais no período de 1997 a 2004, e delinearam algumas considerações acerca da demandas judiciais em saúde neste Estado. O objetivo do estudo era analisar de que maneira o Judiciário garante o direito social a assistência farmacêutica por meio da prestação jurisdicional.

Os resultados demonstraram que a maioria das ações eram compostas por autores individuais representados por advogados particulares. Como justificativas para os pedidos têm-se o risco de vida do paciente, o medicamento prescrito ser o único capaz de controlar a doença, falta de condições financeiras, o direito a saúde ser um direito fundamental garantido por lei, entre outros. (MARQUES, DALLARI, 2007, p. 104)

O Estado, por sua vez, réu nas ações de medicamentos alega em sua defesa que o pedido do autor não se enquadra nas políticas públicas de assistência farmacêutica ou que, nos casos aplicáveis, o medicamento pleiteado não possui registro na ANVISA, além da limitações legais e orçamentárias a que esta sujeito, entre outros. (MARQUES, DALLARI, 2007, p. 104)

De acordo com o estudo em tela, os juízes ao proferirem suas decisões não levam em consideração os elementos da política pública de medicamentos. Tal constatação foi possível em virtude de houve a condenação do Estado em quase $100 \%$ dos casos estudados, havendo situações em que este foi condenado ao fornecimento dos medicamentos nos exatos moldes do pedido autoral, mesmo em casos em que o tratamento pleiteado sequer possuísse registro na ANVISA. As decisões possuem o viés único de reafirmar que o direito à saúde e assistência farmacêutica são integrais e universais a todo 
cidadão, sustentando que questões políticas não podem condicionar e disciplinar o exercício deste direito. (MARQUES, DALLARI, 2007, p. 105)

Como consequência deste fenômeno há um desequilíbrio na tomada de decisões sobre a definição das políticas públicas de saúde que atendem a coletividade e uma sobreposição das necessidades individuais em relação as necessidade da coletividade. (MARQUES, DALLARI, 2007, p. 105)

Diante do aumento no volume de ações, da complexidade do problema da prestação dos serviços públicos e o impacto gerado nas políticas públicas e no orçamento, - Supremo Tribunal Federal instaurou a $4^{\circ}$ Audiência Pública, em 28 de abril de 2009, com o fim de se estudar amplamente este tema. (CLENIO, NETO, 2015, p.164)

Como efeito deste encontro estabeleceu-se, de acordo com Gebran Neto (2015, p.164), a fixação de diretrizes sobre o direito a saúde e a criação do Fórum Nacional da Saúde e dos respectivos Comitês Executivos estaduais da Saúde pelo Conselho Nacional de Justiça com fim de de se estabelecer regras mínimas e de observância obrigatória nas decisões judiciais sobre saúde.

Obviamente, de acordo com Silvia Badim Marques (2007, p. 102), o Poder Judiciário não pode deixar sem resposta os casos que são levados a sua apreciação. Casos estes que implicam no enfrentamento dilemas e decisões trágicas pois tratam-se de questões urgentes versão sobre o sofrimento e a vida das pessoas.

\section{CONSIDERAÇÕES FINAIS}

A Constituição Federal de 1.988 prevê em seu texto um rol de direitos sociais que constituem em prestações positivas do Estado, especifica ser a saúde um direito de todos e um dever do Estado. Assim, a doutrina entende que a redemocratização do Brasil, além de sedimentar os direitos sociais e fundamentais, foi responsável pelo fortalecimento e expansão do Poder Judiciário concomitantemente a consolidação institucional do Ministério Público e a crescente presença das Defensorias Públicas, que permitiu a maior atuação destes em diversas partes do Brasil.

A maior abrangência da constituição permitiu que matérias inseridas no texto constitucional e que antes eram de responsabilidade do processo político majoritário e da legislação ordinária passassem a possuir eficácia imediata. Por fim, o controle de constitucionalidade permite que uma vez desrespeitada a norma constitucional ela será passível de controle pela corte suprema do Brasil.

Associado a isto, outra causa ensejadora da judicialização é a ineficiência do Estado no seu dever prestacional que, por sua vez, muito se dá em razão da insuficiência de recursos. Ocorre que, uma determinação judicial que impõe ao Estado a entrega de um medicamento ou a realização de um procedimento deverá ser cumprida independentemente da existência ou não de recursos. 
Assim, imprescindível que o Poder Judiciário ao ser instado a dirimir questões que envolvem a prestação de saúde àquelas pessoas individualizadas em um processo judicial, o faça seguindo parâmetros e requisitos mínimos, sob pena de abalar ainda mais já ineficiente sistema público de saúde que deverá dar atendimento a toda a coletividade quando, ao não seguir tais parâmetros e requisitos, poderá afetar ainda mais o financiamento público destinado à saúde.

\section{REFERÊNCIAS}

BRASIL, Lei no 9.782, de 26 de janeiro de 1999. Define o sistema nacional de vigilância sanitária, cria a agencia nacional de vigilância sanitária, e dá outras providências. Disponível em «http://www.planalto.gov.br/ccivil_03/leis/l9782.htm〉 Acesso em 30 mar 2018

BRASIL, Lei $n^{\circ} 12.401$ de 28 de abril de 2011. Altera a Lei no 8.080, de 19 de setembro de 1990, para dispor sobre a assistência terapêutica e incorporação de tecnologia em saúde no âmbito do Sistema Único de Saúde - SUS. Disponível em

http://www.planalto.gov.br/ccivil_03/_ato2011-2014/2011/lei//12401.htm. Acesso em 07 nov 2017

ARAÚJO, Luiz Alberto David; JÚNIOR, Vidal Serrano Nunes. Curso de direito constitucional. 10 ed. São Paulo: Saraiva, 2006.

BARROSO, Luis Roberto. Judicialização, ativismo social e legitimidade democrática.

Disponível em

http://www.direitofranca.br/direitonovo/FKCEimagens/file/ArtigoBarroso_para_Selecao.pdf. Acesso em 07 nov 2017

CANOTILHO, J.J. Gomes; MOREIRA, Vital apud SILVA, José Afonso. Curso de direito constitucional positivo. 16.ed. São Paulo: Malheiros, 2017

CARVALHO, Guido Ivan de; SANTOS, Lenir. Sistema único de saúde: Comentários a lei orgânica da saúde (Leis no 8.080/90 e no 8.142/90). 3.ed. Campinas: Editora UNICAMP, 2002

CLENIO, Schulze, NETO, João Pedro Gebran. Direito à saúde a luz da judicialização. Porto Alegre: Verbo Jurídico, 2015

GOMES, Danielle Coutinho Cunha. Aplicação dos princípios e diretrizes do sistema único de saúde (SUS) diante da constituição federal de 1988 e legislação em vigor. Série aperfeiçoamento de magistrados 8: Judicialização da saúde parte II. Disponível em http://www.emerj.tjrj.jus.br/serieaperfeicoamentodemagistrados/paginas/series/8/judicializa caodasaudell_195.pdf. Acesso em 07 nov 2017

GONÇALVES, Sandra Krieger. Judicialização do direito à saúde e os sistema de saúde suplementar no Brasil: Aspectos críticos da fundamentação de decisões judiciais. 302f..Orientador: Cesar Luiz Pasold.Tese (doutorado em Ciência Jurídica) - Universidade do Vale do Itajaí, Santa Catarina, 2015 
GOTTI, Alessandra. Direitos sociais: Fundamentos, regime jurídico, implementação e aferição de resultados. 1.ed. São Paulo :Saraiva, 2012

MACHADO, Felipe Rangel de Souza. Contribuições ao debate da judicialização da saúde no Brasil. Revista de Direito Sanitário, São Paulo, v.9, n.2 p. 73-91, jul/out 2008

MARQUES, Silvia Badim; DALLARI, Sueli Gandolfi. Garantia do direito social à assistência farmacêutica no Estado de São Paulo. Revista Saúde Pública. p. 102-105, 2007. Disponível em http://www.revistas.usp.br/rsp/article/viewFile/32199/34304. Acesso em 08 nov 2017

MENDES, Gilmar Ferreira; BRANCO, Paulo Gustavo Gonet. Curso de direito constitucional. 12 ed. São Paulo: Saraiva, 2017

REMOR, Lourdes de Costa. Controle, avaliação e auditoria do Sistema Único de Saúde: atividades de regulação e fiscalização. Florianópolis: Papa Livro, 2003

SILVA, José Afonso da. Curso de direito constitucional positivo. 16.ed. São Paulo: Malheiros, 2017

WARGAS, Tatiana. Políticas públicas em saúde pública: Informações para tomadores de decisões em saúde pública. Espaço da gestão. São Paulo: 2014. Disponível em http://files.bvs.br/upload/M/2004/Lucchese_Politicas_publicas.pdf. Acesso em 06 nov 2017 